\title{
A Comparative Study of Fatty Acid Content in Yolk of Native Eggs and Ordinary Eggs Available in the Market
}

\author{
Su-Hu Duan, Liu-An Li*, Zai-Qiang Li, Meng-Ran Qin, Zhen-Zhen Fan, Qian Wang, \\ Ke-Yan Zhang, Zhong-Mou Zhang, Bai-Liang Yang and Tian-Ming Jin \\ Tianjin Key Laboratory of Agricultural Animal Breeding and Healthy Husbandry, \\ College of Animal Science and Veterinary Medicine, Tianjin Agricultural University, \\ Tianjin 300384, China
}

\begin{abstract}
A B S T RA C T
In this test, gas chromatographic method was used to determine the fatty acid content of ordinary eggs and native eggs of brands A, B and C. The results indicate that: In the test samples, totally 7 types of SFA, 7 types of MUFA, and 8 types of PUFA were detected. Specifically, no significant difference was found in the content of $\mathrm{C} 14: 0 \sim \mathrm{C} 18: 0(P>0.05)$. The content of $\mathrm{C} 16: 0$ in the yolk of both native eggs and ordinary eggs was high; in the yolk of native eggs of the three brands, the content of C14:1 and C16:1 was both significantly higher than that of ordinary eggs $(P<0.05)$; the content of $C 17: 1$ in yolk of native eggs of brand $\mathrm{A}$ was significantly higher than that of brand $\mathrm{C}$ native eggs $(P<0.05)$; the content of $\mathrm{C} 18: 2 \mathrm{n} 6 \mathrm{t}$ and C20:2 in yolk of ordinary eggs and brand $\mathrm{C}$ eggs was significantly higher than that of brand A and B native eggs $(P<0.05)$; the content of $\mathrm{C} 18: 2 \mathrm{n} 6 \mathrm{c}$ in yolk of ordinary eggs was significantly higher than that of brands A and $\mathrm{C}$ native eggs $(P<0.05)$; the content of $\mathrm{C} 22$ :6n 3 in yolk of ordinary eggs was significantly higher than that of brand A native eggs $(P<0.05)$; there was no significant difference in $\omega-6 / \omega-3$ PUFA ratio of yolk of ordinary eggs and native eggs of three brands $(P>0.05)$. The study provides theoretical and practical reference for customers for selection of eggs.
\end{abstract}

Article Information
Received 10 January 2019
Revised 19 July 2019
Accepted 01 October 2019
Available online 06 March 2020
Authors' Contribution
L-AL designed this study. S-HD, Z-QL
and M-rQ conducted the experiments.
S-HD, Z-ZF, QW, K-YZ, Z-MZ
analyzed the main data. B-LY and
T-MJ supervised the study. L-AL and
S-HD wrote the manuscript.
Key words
Native eggs, Ordinary eggs, Yolk,
Fatty acid, Content comparison

\section{INTRODUCTION}

A $\mathrm{t}$ present, in addition to the price, people are attaching an increasing importance to nutritional value of eggs when buying eggs in the market. Native eggs are also called "farm eggs" and "free-range eggs", and are tasty, with premium quality and rich nutrients. Furthermore, they are healthy. Yolk of eggs contains a variety of nutrient substances, and fatty acid is one of the main substances. People may get beneficial fatty acid that is necessary for our body by eating eggs (Shinn et al., 2018).

Fatty acids are classified into saturated fatty acid(SFA), monounsaturated fatty acid (MUFA), and polyunsaturated fatty acid (PUFA) by the unsaturation degree of the carbon chain (Duan et al., 2019). Specifically, MUFA has functions including anti-inflammation, prevention and delay of type- 2 diabetes, and inhibition of atherosis; PUFA has functions including anti-inflammation, anti-cancer, promotion of growth and development and protection of heart and cerebral vessels (Diep et al., 2000; Wai et al., 2015; Manni et al., 2015).

Corresponding author: anliuli2003@163.com 0030-9923/2020/0003-1039 \$ 9.00/0

Copyright 2020 Zoological Society of Pakistan
By now, many studies have been carried out on enrichment of fatty acid and content of fatty acid in eggs. However, there have been very few reports on comparative study of fatty acid content in native eggs and ordinary eggs. In this study, ordinary eggs and native eggs of different brands available in the market were taken as the objects of study to determine the content of fatty acid in yolk, so as to find out the difference in fatty acid content in yolk of native eggs and ordinary eggs, thus providing theoretical and practical reference for customers for selection of eggs.

\section{MATERIALS AND METHODS}

\section{Materials}

Twenty five eggs were randomly selected from the ordinary eggs, and native eggs of brands A, B and C with similar date of manufacturing and date of packaging in a large supermarket of Tianjin. The 37 types of standard substances mixed with constituent FAME and triglyceride undecanoate (C11:0) were purchased from Nu-Chek of America; petroleum ether (boiling range $30^{\circ} \mathrm{C}-60^{\circ} \mathrm{C}$, analytically pure), methyl alcohol (chromatographically pure) and hydrochloric acid (analytically pure) were purchased from Tianjin Fengchuan Chemical Reagent 
Technology Co., Ltd. Normal hexane (chromatographically pure) was purchased from Tianjin Fine Chemical Engineering Research Institute. The 15 boron trifluoridemethanol (analytically pure) was purchased from Panjin Yanfeng Technology Co., Ltd. Absolute ether (analytically pure) was purchased from Rionlon Bohua (Tianjin) Medical Chemistry Co., Ltd. Pyrogallic acid (analytically pure) was purchased from Tianjin Guangfu Fine Chemical Engineering Research Institute. Anhydrous sodium sulfate (analytically pure) was purchased from Tianjin Bodi Chemical Engineering Co., Ltd. Sodium chloride was purchased from Tianjin Jizhun Chemical Reagent Co., Ltd.; 95\% ethyl alcohol (analytically pure) was purchased from Tianjin Fuyu Fine Chemical Engineering Co., Ltd. Sodium hydroxide (analytically pure) was purchased from Bo'oute (Tianjin) Chemical Trade Co., Ltd.; $50 \mathrm{~mL}$ centrifuge tube; gas chromatography sample bottle.

\section{Equipment and instrument}

The gaschromatograph 7890B was purchased from Agilent; capillary-column chromatography SP2560 was purchased from Supelco; thermostat water bath was purchased from Shanghai Zhicheng Analytical Instrument Manufacturing Co., Ltd.; analytical balance was purchased from Shanghai Shunning Hengping Scientific Instrument Co., Ltd. The above instrument and equipment were all provided by Lab of the School of Animal Science and Animal Medicine of Tianjin Agricultural College.

\section{Method}

Five eggs were randomly selected from each type of eggs. The yolk was evenly mixed and the specimen was taken and hydrolyzed, fat extracted and saponified, followed by methyl esterification and conversion of fatty acid. The content of fatty acid was carried out according to GB5009.168-2016 standard.

\section{Gas-phase conditions}

Gas chromatographic column: SP2560 $(100 \mathrm{~m} \times 250$ $\mu \mathrm{m} \times 0.2 \mu \mathrm{m}$ ); chromatographic column flow: $1 \mathrm{~mL} / \mathrm{min}$; hydrogen flow: $30 \mathrm{~mL} / \mathrm{min}$; carrier gas: He; split ratio: 20:1; FID detector; detector temperature: $280^{\circ} \mathrm{C}$; column oven temperature: $250{ }^{\circ} \mathrm{C}$; column oven temperature raising program: starting temperature: $140{ }^{\circ} \mathrm{C}$, holding for $5 \mathrm{~min}$; then the temperature rose at a rate of $4{ }^{\circ} \mathrm{C} /$ min to $220{ }^{\circ} \mathrm{C}$, and then at a rate of $0.5^{\circ} \mathrm{C} / \min$ to $230^{\circ} \mathrm{C}$; eventually, the temperature rose at a rate of $4{ }^{\circ} \mathrm{C} / \mathrm{min}$ to $240{ }^{\circ} \mathrm{C}$, holding for $15 \mathrm{~min}$; make-up gas rate: $25 \mathrm{~mL} / \mathrm{min}$; sample size: $5 \mu \mathrm{L}$.

\section{Statistical analysis}

SPSS 20.0 software was used and one-way ANOVA analysis, Duncan' D was used for multiple comparisons among mean values and significance testing. All data used in the test were expressed with mean value \pm standard error. $P<0.05$ was deemed as significant difference.

\section{RESULTS}

\section{Fatty acids content of yolk}

As shown in Figure 1, there was no significant difference $(P>0.05)$ in the content of total fatty acids (FA), SFA, unsaturated fatty acid (UFA), MUFA, and $\omega-3$ polyunsaturated fatty acid ( $\omega-3$ PUFA) in yolk of ordinary eggs and native eggs available in the market. The content of PUFA and $\omega-6$ Polyunsaturated fatty acid ( $\omega-6$ PUFA) was significantly higher than that of the native eggs of the three brands $(P<0.05)$; there was no significant difference in content of total PUFA and $\omega-6$ PUFA in yolk of the three brands of native eggs $(P>0.05)$.

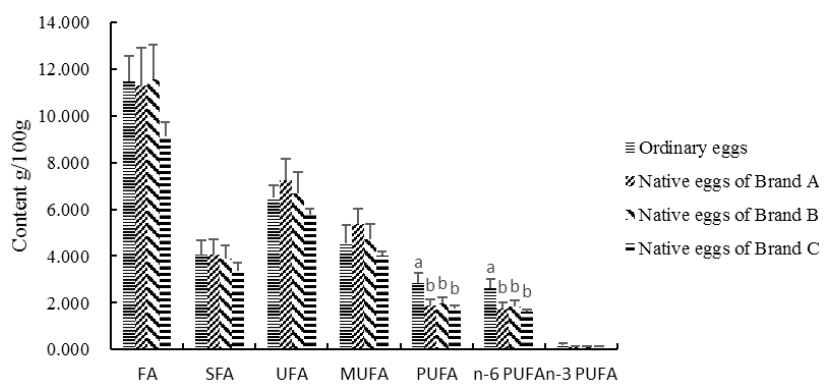

Fig. 1. Fatty acids contents of yolk of native eggs and ordinary eggs. Note: The lowercase letters represent the significant differences among different groups $(P<0.05)$. The same applies below.

\section{Saturated fatty acids (SFA) in yolk}

As indicated in Table I, 7 types of SFA were detected in the yolk of native eggs and ordinary eggs available in the market. Specifically, there was no significant difference in the content of C14:0 C18:0 $(P>0.05)$; the content of $\mathrm{C} 16: 0$ in yolk of native eggs and ordinary eggs was high; the content of SFA C22:0 in yolk of ordinary eggs and brand $\mathrm{C}$ native eggs was significantly higher than that of native eggs of brands $\mathrm{A}$ and $\mathrm{B}(P<0.05)$.

\section{Monounsaturated fatty acids (MUFA) in yolk}

According to Table II, seven MUFA were detected in the yolk of ordinary eggs and eggs of the three brands available in the market. Specifically, the content of C14:1 and C16:1 in yolk of native eggs. 
Table I. Comparison of content (g/100g) of various SFA in yolk of native eggs and ordinary eggs available in the market.

\begin{tabular}{lllll}
\hline Types of fatty acid & Ordinary eggs & Native eggs of brand A & Native eggs of brand B & Native eggs of brand C \\
\hline C4:0 & ND & ND & ND & ND \\
C6:0 & ND & ND & ND & ND \\
C8:0 & ND & ND & ND \\
C10:0 & ND & ND & ND \\
C11:0 & ND & ND & ND \\
C12:0 & ND & ND & ND \\
C13:0 & ND & ND & ND \\
C14:0 & $0.028 \pm 0.003$ & $0.029 \pm 0.004$ & $0.033 \pm 0.006$ & $0.022 \pm 0.004$ \\
C15:0 & $0.006 \pm 0.002$ & $0.005 \pm 0.001$ & $0.006 \pm 0.002$ & $0.003 \pm 0.001$ \\
C16:0 & $2.916 \pm 0.480$ & $2.794 \pm 0.442$ & $2.459 \pm 0.144$ \\
C17:0 & $2.927 \pm 0.414$ & $0.028 \pm 0.003$ & $0.024 \pm 0.003$ & $0.039 \pm 0.015$ \\
C18:0 & $0.013 \pm 0.004$ & $1.094 \pm 0.208$ & $1.001 \pm 0.164$ & $0.813 \pm 0.033$ \\
C20:0 & $1.069 \pm 0.167$ & ND & ND & ND \\
C21:0 & ND & ND & ND & $0.019 \pm 0.009$ \\
C22:0 & $0.016 \pm 0.015$ & $0.003^{b} \pm 0.001$ & $0.002^{b} \pm 0.001$ & $0.009^{a} \pm 0.002$ \\
C23:0 & $0.016^{a} \pm 0.004$ & ND & ND & ND \\
C24:0 & ND & ND & ND & ND \\
\hline ND & ND & ND &
\end{tabular}

Note: ND indicates there was no result, the difference in the lowercase letters of the peer data indicates that the difference is significant $(P<0.05)$, and the same lowercase letters indicate that the difference is not significant $(P>0.05)$. the same below.

Table II. Comparison of content (g/100g) of various MUFA in yolk of native eggs and ordinary eggs available in the market.

\begin{tabular}{lllll}
\hline Types of fatty acid & Ordinary eggs & Native eggs of brand A & Native eggs of brand B & Native eggs of brand C \\
\hline $\mathrm{C} 14: 1$ & ND & $0.005^{\mathrm{a}} \pm 0.001$ & $0.005^{\mathrm{a}} \pm 0.001$ & $0.005^{\mathrm{a}} \pm 0.001$ \\
$\mathrm{C} 15: 1$ & $\mathrm{ND}$ & $0.293^{\mathrm{a}} \pm 0.050$ & $\mathrm{ND}$ & $\mathrm{ND}$ \\
$\mathrm{C} 16: 1$ & $0.142^{\mathrm{b}} \pm 0.034$ & $0.018^{\mathrm{a}} \pm 0.004$ & $0.280^{\mathrm{a}} \pm 0.052$ & $0.286^{\mathrm{a}} \pm 0.023$ \\
$\mathrm{C} 17: 1$ & $0.008^{\mathrm{ab}} \pm 0.002$ & $0.011 \pm 0.001$ & $0.013^{\mathrm{a}} \pm 0.006$ & $0.004^{\mathrm{b}} \pm 0.002$ \\
$\mathrm{C} 18: 1 \mathrm{n} 9 \mathrm{t}$ & $0.056 \pm 0.028$ & $5.032 \pm 0.629$ & $0.012 \pm 0.001$ & $0.077 \pm 0.035$ \\
$\mathrm{C} 18: 1 \mathrm{ln} 9 \mathrm{c}$ & $4.322 \pm 0.791$ & $\mathrm{ND}$ & $4.404 \pm 0.590$ & $3.746 \pm 0.182$ \\
$\mathrm{C} 20: 1$ & $0.010^{\mathrm{a}} \pm 0.003$ & $\mathrm{ND}$ & $\mathrm{ND}$ & $0.012^{\mathrm{a}} \pm 0.001$ \\
$\mathrm{C} 22: \ln 9$ & $0.008^{\mathrm{ab}} \pm 0.004$ & $\mathrm{ND}$ & $0.001^{\mathrm{b}} \pm 0.001$ & $0.010^{\mathrm{a}} \pm 0.004$ \\
$\mathrm{C} 24: 1$ & $\mathrm{ND}$ & $\mathrm{ND}$ & $\mathrm{ND}$ \\
\hline
\end{tabular}

Polyunsaturated fatty acids (PUFA) in yolk

According to Table III, 8 PUFA were detected in ordinary eggs and native eggs of 3 brands available in the market. Specifically, the content of C18:2n6t and C20:2 in yolk of ordinary eggs and native eggs of brand $\mathrm{C}$ was significantly higher than that of native eggs of brands $\mathrm{A}$ and B $(P<0.05)$; no $\mathrm{C} 20: 2$ was detected in yolk of brand $\mathrm{B}$ native eggs; the content of $\mathrm{C} 18: 2 \mathrm{n} 6 \mathrm{c}$ in yolk of ordinary eggs was significantly higher than that of brands $\mathrm{A}$ and $\mathrm{C}$ native eggs $(P<0.05)$; no $\mathrm{C} 20$ : $3 \mathrm{n} 6$ was detected in yolk of brand $\mathrm{C}$ native eggs; there was no significant difference in content of $\mathrm{C} 20$ : $4 \mathrm{n} 6$ in yolk of ordinary eggs and native eggs of the three brands $(P>0.05)$; the content of $\mathrm{C} 22$ : $6 \mathrm{n} 3$ in yolk of ordinary eggs was significantly higher than that of brand A native eggs $(P<0.05)$; there was no significant difference in content of $\mathrm{C} 22$ : $6 \mathrm{n} 3$ among native eggs of the three brands $(P>0.05)$. 
Table III. Comparison of content (g/100g) of various PUFA in yolk of native eggs and ordinary eggs available in the market.

\begin{tabular}{lllll}
\hline Types of fatty acid & Ordinary eggs & Native eggs of brand A & Native eggs of brand B & Native eggs of brand C \\
\hline $\mathrm{C} 18: 2 \mathrm{n} 6 \mathrm{t}$ & $0.037^{\mathrm{a}} \pm 0.016$ & $0.003^{\mathrm{b}} \pm 0.001$ & $0.003^{\mathrm{b}} \pm 0.001$ & $0.040^{\mathrm{a}} \pm 0.010$ \\
$\mathrm{C} 18: 2 \mathrm{n} 6 \mathrm{c}$ & $2.064^{\mathrm{a}} \pm 0.156$ & $1.461^{\mathrm{b}} \pm 0.226$ & $1.562^{\mathrm{ab}} \pm 0.253$ & $1.358^{\mathrm{b}} \pm 0.076$ \\
$\mathrm{C} 18: 3 \mathrm{n} 6$ & $0.016 \pm 0.003$ & $0.011 \pm 0.002$ & $0.013 \pm 0.002$ & $0.010 \pm 0.001$ \\
$\mathrm{C} 18: 3 \mathrm{n} 3$ & $0.063 \pm 0.010$ & $0.047 \pm 0.008$ & $0.053 \pm 0.007$ & $0.041 \pm 0.007$ \\
$\mathrm{C} 20: 2$ & $0.010^{\mathrm{a}} \pm 0.005$ & $\mathrm{ND}$ & $\mathrm{ND}$ & $0.005^{\mathrm{a}} \pm 0.003$ \\
$\mathrm{C} 20: 3 \mathrm{n} 6$ & $0.011^{\mathrm{a}} \pm 0.004$ & $\mathrm{ND}$ & $0.003^{\mathrm{ab}} \pm 0.003$ & $0.009^{\mathrm{a}} \pm 0.003$ \\
$\mathrm{C} 20: 3 \mathrm{n} 3$ & $\mathrm{ND}$ & $\mathrm{ND}$ & $\mathrm{ND}$ & $\mathrm{ND}$ \\
$\mathrm{C} 20: 4 \mathrm{n} 6$ & $0.223 \pm 0.056$ & $0.298 \pm 0.032$ & $0.248 \pm 0.022$ & $0.215 \pm 0.017$ \\
$\mathrm{C} 22: 2$ & $\mathrm{ND}$ & $\mathrm{ND}$ & $\mathrm{ND}$ & $\mathrm{ND}$ \\
$\mathrm{C} 20: 5 \mathrm{n} 3$ & $\mathrm{ND}$ & $\mathrm{ND}$ & $\mathrm{ND}$ & $\mathrm{ND}$ \\
$\mathrm{C} 22: 6 \mathrm{n} 3$ & $0.113^{\mathrm{a}} \pm 0.036$ & $0.056^{\mathrm{b}} \pm 0.013$ & $0.068^{\mathrm{ab}} \pm 0.015$ & $0.084^{\mathrm{ab}} \pm 0.006$ \\
\hline
\end{tabular}

Of the three brands was significantly higher than that of ordinary eggs $(P<0.05)$; the content of $\mathrm{C} 17: 1$ in yolk of native eggs of brand A was slightly higher than that of native eggs of brand $\mathrm{C}(P<0.05)$; compared with ordinary eggs and native eggs of brand $\mathrm{C}$, native eggs of brands $\mathrm{A}$ and $\mathrm{B}$ were found to contain no $\mathrm{C} 20: 1$; no $\mathrm{C} 22: 1 \mathrm{n} 9$ was detected in yolk of native eggs of brand A; neither C15:1 nor C24:1 was detected in ordinary eggs and the three brands of native eggs.

As indicated in Figure 2, there was no significant difference in $\omega-6 / \omega-3$ PUFA ratio of yolk of ordinary eggs and native eggs of three brands available in the market $(P>0.05)$. The ratios order is as follows: ordinary eggs $<$ native eggs of brand $\mathrm{C}<$ native eggs of brand $\mathrm{A}<$ native eggs of brand B.

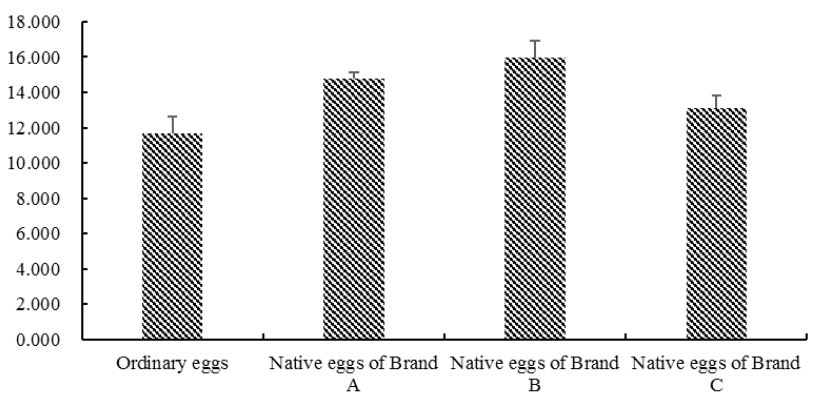

Fig. 2. The $\omega-6 / \omega-3$ PUFA ratio of yolk of ordinary eggs and native eggs of three brands.

\section{DISCUSSION}

C16:0 (palmitic acid), as one of the saturated fatty acids, plays a substantial role in growth and metabolism of body cells. Related studies indicate that the palmitic acid is able to induce cell death and autophagy, and change the phospholipid level in the myocardial cell, thus posing an impact on the functions of mitochondria in cells (Ostrander et al., 2001; Chang et al., 2016). This study shows that the content of C16:0 in yolk of ordinary eggs and native eggs was the highest, without significant difference. This result is similar to the study result of Kaya et al. (2018).

The study of Feng et al. (2016) indicates that there was significant difference in content of C16: 1 (palmitoleic acid) and C18:1 (oleic acid) among the three types of eggs, namely, Lhasa white chicken, Tibetan chicken and Liuhonggu fragrant chicken. In the results of this study, the content of C16:1 of eggs of the three brands was significantly higher than that of ordinary eggs. The reason might be related to the species, daily ration and feeding model of the laying hens. C18: $1 \mathrm{n} 9 \mathrm{c}$ is an important MUFA. In this study, the content of $\mathrm{C} 18: \ln 9 \mathrm{c}$ in yolk reached $3.746 \sim 5.032 \mathrm{~g} / 100 \mathrm{~g}$, which was generally lower than the study result of Zhang et al. (2018). The reason might be related to the species of chicken, composition of feedstuff and feeding model.

PUFA, $\omega-3$ PUFA and $\omega-6$ PUFA in particular, are essential fatty acids that our human body is not able to synthesize and has to get from our food. The C18:2n6 (linoleic acid) and (arachidonic acid), as $\omega-6$ PUFA, could be transformed into $\mathrm{C} 18: 3 \mathrm{n} 6$ ( $\gamma$ - linolenic acid) through metabolism; C18:3n3 ( $\alpha$-linolenic acid), as $\omega-3$ PUFA, could be transformed into C20:5n3 (EPA) and C22:6n3 (DHA) through metabolism (Silvia et al., 2013). C18:2n6c is able to adjust the cholesterol content in our body (Yang et al., 2017; Harauma et al., 2017). The study of Devlin et al. (2017) indicates that intake of a proper amount of $\mathrm{C} 20: 4 \mathrm{n} 6$ and C22:6n3 was good for development of 
cranial nerve of infants (Angela et al., 2017). The study of Cherian (2017) indicates that addition of flaxseed into the daily ration of laying hens could result in settlement of a great amount of $\omega-3$ PUFA in the yolk, with significant increase of deposition of C18:3n3 (Cherian 2017). Results of this study indicate that the $\mathrm{C} 18: 2 \mathrm{n} 6 \mathrm{c}$ content in yolk of native eggs available in the market was lower than that of ordinary eggs; there was no significant difference in content of C20: $4 \mathrm{n} 6$ in yolk of ordinary eggs and native eggs of three brands; the content of C20: $4 \mathrm{n} 6$ in yolk of brand $\mathrm{A}$ and $\mathrm{B}$ native eggs was higher than that of ordinary eggs. The content of C22:6n3 in yolk of ordinary eggs was significantly higher than that of brand A native eggs. This means that the feedstuff for the two types of laying hens was different, or there was difference in the nutritional ingredients contained in the feedstuff.

Related studies indicate that the ideal ratio of acceptable daily intake of $\omega-6$ PUFA to $\omega-3$ PUFA in the diet was 2:1. Excessive intake of $\omega-6$ PUFA may result in reduction in intake of $\omega-3$ PUFA such as C20:5n 3 and C22:6n3 (Simopoulos, 2008; Harris et al., 2009). The study result shows that the range of $\omega-6$ PUFA to $\omega-3$ PUFA ratio in yolk of ordinary eggs and native eggs available in the market is from 11 to 16 . According to the ratio range, the eggs available in the market are not quite ideal for consumers.

\section{CONCLUSIONS}

Seven types of SFA, 7 types of MUFA, and 8 types of PUFA were detected in the yolk of ordinary eggs and native eggs of three brands available in the market. Specifically, no significant difference was found in the content of $\mathrm{C} 14: 0 \sim \mathrm{C} 18: 0(P>0.05)$. The content of $\mathrm{C} 16: 0$ in the yolk of both native eggs and ordinary eggs was high; in the yolk of native eggs of the three brands, the content of $\mathrm{C} 14: 1$ and $\mathrm{C} 16: 1$ was both significantly higher than that of ordinary eggs $(P<0.05)$; the content of $\mathrm{C} 17: 1$ in yolk of native eggs of brand $\mathrm{A}$ was significantly higher than that of brand $\mathrm{C}$ native eggs $((P<0.05)$; the content of $\mathrm{C} 18$ : $2 \mathrm{n} 6 \mathrm{t}$ and C20:2 in yolk of ordinary eggs and brand C eggs was significantly higher than that of brand $\mathrm{A}$ and $\mathrm{B}$ native eggs $(P<0.05)$; the content of $\mathrm{C} 18: 2 \mathrm{n} 6 \mathrm{c}$ in yolk of ordinary eggs was significantly higher than that of brands $\mathrm{A}$ and $\mathrm{C}$ native eggs $(P<0.05)$; the content of $\mathrm{C} 22$ : $6 \mathrm{n} 3$ in yolk of ordinary eggs was significantly higher than that of brand $\mathrm{A}$ native eggs $(P<0.05)$; there was no significant difference in $\omega-6 / \omega-3$ PUFA ratio of yolk of ordinary eggs and native eggs of three brands $(P>0.05)$.

\section{ACKNOWLEDGEMENTS}

The study has been supported by Major Special
Scientific and Technological Project and Engineering Project of Tianjin (18ZXBFNC00310); the "131" Innovative Talent Team Building Project of Tianjin (20180318); the Candidate Funding Project under "Young and Middle Aged Innovative Backbone Talents Cultivation Program" for Colleges and Universities in Tianjin (JJWRH [2017] No. 23) and Tianjin Enterprise Technology Commissioner Project (19JCTPJC59500).

\section{Statement of conflict of interest}

We declare that there is no conflict of interests regarding the publication of the manuscript.

\section{REFERENCES}

Angela, D., Cecil, C., Roger, D., Julie, M., Deanna, M.C., Karin, Y. M., Sheila, I. and Ruth, G., 2017. Developmental outcomes at 24 months of age in toddlers supplemented with arachidonic acid and docosahexaenoic acid: results of a double blind randomized, controlled trial. Nutrients, 9: 975-992. https://doi.org/10.3390/nu9090975

Chang, F., Liu, J., Fu, H., Wang, J., Li, F., Yue, H. and Yin, D., 2016. Gsk-3 $\beta$ promotes pa-induced apoptosis through changing $\beta$-arrestin 2 nucleus location in h9c2 cardiomyocytes. Apoptosis, 21: 1045-1055. https://doi.org/10.1007/s10495-016$1272-\mathrm{z}$

Cherian, G., 2017. Chapter 34 - Supplemental flax and impact on n-3 and n-6 polyunsaturated fatty acids in eggs. In: Egg innovations and strategies for improvements (ed. Y.H. Patricia). Academic Press, United States. pp. 365-372. https://doi.org/10.1016/ B978-0-12-800879-9.00034-2

Devilin, A.M., Chau, C.M.Y., Dyer, R., Matheson, J., McCarthy, D., Yurko-Mauro, Karin., Innis, Sheila. M. and Grunau, R.E., 2017. Developmental outcomes at 24 months of age in toddlers supplemented with arachidonic acid and docosahexaenoic acid: Results of a double blind randomized, controlled trial. Nutrients, 9: 975-987.

Diep, Q.N., Touyz, R.M. and Schiffrin, E.L., 2000. Docosahexaenoic acid, a peroxisome proliferatoractivated receptor-alpha ligand, induces apoptosis in vascular smooth muscle cells by stimulation of $\mathrm{p} 38$ mitogen-activated protein kinase. Hypertension, 36: 851-855. https://doi.org/10.1161/01.HYP.36.5.851

Duan, S.H., Li, L.A., Li, Z.Q., Qin, M.R., Fan Z.Z., Zhang, K.Y., Wang, Q., Zhang Z.M. and Yang, B.L, 2019. Comparison of yolk fatty acids in market available black-bone chicken eggs and ordinary chicken eggs. Pakistan J. Zool., 51: 2107-2115. 
Feng, J., Wang, Y., Zang, L., Liu, H.J., Peng, D. and Ma, X.Y., 2016. Comparative study on nutritional components of eggs from different breeds of laying hens. Anim. Husb. Feed Sci., 37: 4-9.

Harauma, A., Yasuda, H., Hatanaka, E., Nakamura, M.T., Salem, N. and Moriguchi, T., 2017. The essentiality of arachidonic acid in addition to docosahexaenoic acid for brain growth and function. Prostagl. Leukotr. Essent. Fatty Acids (PLEFA), 116: 9-18. https://doi.org/10.1016/j.plefa.2016.11.002

Harris, W.S., Mozaffarian, D., Rimm, E., Kris-Etherton, P., Rudel, L.L., Appel, L.J., Engler, M.M., Engler, M.B. and Sacks, F., 2009. Omega-6 fatty acids and risk for cardiovascular disease: a science advisory from the american heart association nutrition subcommittee of the council on nutrition, physical activity, and metabolism; council on cardiovascular nursing; and council on epidemiology and prevention. Circulation, 119: 902-907. https://doi. org/10.1161/CIRCULATIONAHA.108.191627

Kaya, H., Kaya, A., Macit, M. and Çelebi, S., 2018. Effects of dietary copper supplementation on performance, egg quality parameters, yolk cholesterol and fatty acid profiles in laying hens. Indian J. Anim. Res., 52: 1623-1627. https://doi. org/10.18805/ijar.B-830

Manni, A., El-Bayoumy, K., Skibinski, C.G., Thompson, H.J., Santucci-Pereira, J., Bidinotto, L.T. and Russo, J., 2015. Combination of antiestrogens and Omega-3 fatty acids for breast cancer prevention. BioMed. Res. Int., 9: 638-645. https://doi. org/10.1155/2015/638645

Ostrander, D.B., Sparagna, G.C., Amoscato, A.A., Mcmillin, J.B. and Dowhan, W., 2001. Decreased cardiolipin synthesis corresponds with cytochrome release in palmitate-induced cardiomyocyte apoptosis. J. biol. Chem., 276: 38061-38068.

Shinn, S.E., Proctor, A. and Baum, J.I., 2018. Egg yolk as means for providing essential and beneficial fatty acids. J. Am. Oil Chem. Soc., 95: 5-11. https:// doi.org/10.1002/aocs. 12008

Silvia, Lorente-Cebrián, André, G.V., Costa, Navas-Carretero, S., María Zabala, J., Alfredo, Martínez., María, J. and Moreno-Aliaga, 2013. Role of omega-3 fatty acids in obesity, metabolic syndrome, and cardiovascular diseases: a review of the evidence. J. Physiol. Biochem., 69: 633-651. https://doi.org/10.1007/s13105-013-0265-4

Simopoulos. A.P., 2008. The importance of the Omega-6/ Omega-3 fatty acid ratio in cardiovascular disease and other chronic diseases. Exp. Biol. Med., 233: 674-688. https://doi.org/10.3181/0711-MR-311

Wai, S., Wai, L. and Kwok, L., 2015. Omega-3 polyunsaturated fatty acids trigger cell cycle arrest and induce apoptosis in human neuroblastoma LAN-1 Cells. Nutrients, 7: 6956-6973. https://doi. org/10.3390/nu7085319

Yang, M., Liang, S.H., Wang, M.Y. and Zhang, M., 2017. Physicochemical properties and fatty acid compositions of egg yolk oils from four avian species. J. Henan Univ. Technol. (Nat. Sci. Ed.), 38: 47-51.

Zhang, J.B., Tian, C.Y., Yang, X.L., Hong, Z.H., Qin, S.Y. and Yang, H., 2018. Comparative study on fatty acid of ordinary eggs and native eggs of two brands from Beijing, Tianjin and Baoding city. $J$. Tianjin Agric. Univ., 25: 34-37+46. 